\title{
Age-related differences in torque in angle-specific and peak torque hamstring to quadriceps ratios in female soccer players from 11 to 18 years old: A Cross-sectional study
}

Andrade, Marilia S ; Junqueira, Marina S ; Andre Barbosa De Lira, Claudio ; Vancini, Rodrigo L ; Seffrin, Aldo ; Nikolaidis, Pantelis T ; Rosemann, Thomas ; Knechtle, Beat

Abstract: The aim of this study was to evaluate and compare the hamstring $(\mathrm{H})$ and quadriceps $(\mathrm{Q})$ strength, bilateral difference and balance ratios in female soccer players. Ninety-three athletes from three age groups: under 13 (U13), 15 (U15) and 18 (U18) participated in the study performing isokinetic tests to measure peak torque, total work, average power and torque at $30^{\circ}$ of thigh muscles. Conventional strength balance ratios, angle-specific balance ratio and bilateral strength difference were evaluated. There was bilateral strength difference for extensor muscles total work $(p=0.02)$ in $U 13$ and flexor muscles peak torque $(p=0.02)$ in U15. All variables were superior in U15 than U13 ( $<$.05). There was no strength difference between U15 and U18. Balance ratios did not differ between sides or age groups. The study showed that although peak torque values were higher in U15 than in U13, balance ratios were similar.

DOI: https://doi.org/10.1080/15438627.2020.1742713

Posted at the Zurich Open Repository and Archive, University of Zurich ZORA URL: https://doi.org/10.5167/uzh-187837

Journal Article

Accepted Version

Originally published at:

Andrade, Marilia S; Junqueira, Marina S; Andre Barbosa De Lira, Claudio; Vancini, Rodrigo L; Seffrin, Aldo; Nikolaidis, Pantelis T; Rosemann, Thomas; Knechtle, Beat (2021). Age-related differences in torque in anglespecific and peak torque hamstring to quadriceps ratios in female soccer players from 11 to 18 years old: A Cross-sectional study. Research in Sports Medicine, 29(1):77-89.

DOI: https://doi.org/10.1080/15438627.2020.1742713 


\section{Age-related differences in torque in angle-specific and peak torque hamstring to quadriceps ratios in female soccer players from 11 to 18 years old: A cross-sectional study}

Marilia S. Andrade ${ }^{1}$, Marina S. Junqueira ${ }^{1}$, Claudio A. B. de Lira ${ }^{2}$, Rodrigo L. Vancini ${ }^{3}$, Aldo Seffrin ${ }^{1}$, Pantelis T. Nikolaids ${ }^{4}$, Thomas Rosemann ${ }^{5}$, Beat Knechtle ${ }^{5,6 *}$

${ }^{1}$ Laboratório de Fisiologia do Exercício, Escola Paulista de Medicina, Departamento de Fisiologia, Universidade Federal de São Paulo, São Paulo, Brazil.

${ }^{2}$ Laboratório de Avaliação do Movimen to Humano, Faculdade de Educação Física e Dança, Setor de Fisiologia Humana e do Exercício, Universidade Federal de Goiás, Goiânia, Brazil.

${ }^{3}$ Centro de Educação Física e Desportos, Departamento de Desportos, Universidade Federal do Espírito Santo, Vitória, Brazil.

${ }^{4}$ Exercise Physiology Laboratory, Nikaia, Greece.

${ }^{5}$ Institute of Primary Care, University of Zurich.

${ }^{6}$ Medbase St. Gallen Am Vadianplatz, St. Gallen, Switzerland.
Marilia S. Andrade
Marina S. Junqueira
Claudio A. B. de Lira
Rodrigo L. Vancini
Aldo Seffrin
Pantelis T. Nikolaidis
Thomas Rosemann
Beat Knechtle

\author{
marilia1707@gmail.com \\ marinasj95@gmail.com \\ andre.claudio@gmail.com \\ rodrigoluizvancini@gmail.com \\ netoseffrin@gmail.com \\ pademil@hotmail.com \\ thomas.rosemann@usz.ch \\ beat.knechtle@hispeed.ch
}

\author{
Corresponding author \\ Prof. Dr. med. Beat Knechtle \\ Medbase St. Gallen Am Vadianplatz \\ Vadianstrasse 26 \\ 9001 St. Gallen \\ Switzerland \\ Telephone $\quad+41(0) 712269300$ \\ Telefax $\quad+41(0) 712269301$ \\ E-mail_beat.knechtle@hispeed.ch
}




\section{ABSTRACT}

37 The aim of this study was to evaluate and compare the hamstring $(\mathrm{H})$ and quadriceps $(\mathrm{Q})$ strength,

38 bilateral difference and balance ratios in female soccer players. Ninety-three athletes from three age

39 groups: under 13 (U13), 15 (U15) and 18 (U18) participated in the study performing isokinetic tests

40 to measure peak torque, total work, average power and torque at $30^{\circ}$ of thigh muscles. Conventional

41 strength balance ratios, angle-specific balance ratio and bilateral strength difference were evaluated.

42 There was bilateral strength difference for extensor muscles total work $(p=0.02)$ in U13 and flexor

43 muscles peak torque $(\mathrm{p}=0.02)$ in U15. All variables were superior in U15 than U13 $(\mathrm{p}<.05)$. There

44 was no strength difference between U15 and U18. Balance ratios did not differ between sides or age

45 groups. The study showed that although peak torque values were higher in U15 than in U13, balance

46 ratios were similar.

47 Keywords: athletes1, exercise2, women3; isokinetic4, footballs, strength imbalance6. 


\section{INTRODUCTION}

60 The muscular strength profiles of athletes involved with soccer can provide important data about the

61 muscular adaptations due this specific sport demand which occur due to years of sport practice

62 (Voutselas et al., 2007). Furthermore, muscular strength profiles also are useful to better

63 understanding sport performance and for injury risk management (Siqueira et al., 2002).

64 Previous research has demonstrated that the lower limbs strength and power, mainly for quadriceps

65 and hamstrings muscles, are important factors for basic soccer actions, such as, sprint or fast changes

66 of direction, passing, jumping, kicking the ball or pace quickly (Reilly and Thomas, 1975; Rösch et

67 al., 2000; Stolen et al., 2005). The intense muscular requirement presented in these activities is

68 characterized by an asymmetric kinetic pattern (Hewett et al., 1999; Kotzamanidis et al., 2005),

69 which may cause strength asymmetry (Arnason et al., 2004). Fousekis et al (2010) reported that this

70 strength asymmetry is even more common in athletes with short or intermediate training experience.

71 A deficit range less than $10 \%$, between the lower limbs, has been considered an acceptable value

72 (Daneshjoo et al., 2013). While, strength asymmetric higher than $15 \%$ increased the hamstrings

73 injury risk in 2.6 times (Knapik et al., 1991).

74 Not less important, the strength balance ratio between quadriceps and hamstrings muscles has also

75 been described as an important variable to assess the joint stability. Indeed, these muscles play a

76 crucial role in affecting anterior tibial translation and anterior cruciate ligament (ACL) strain (Hughes

77 and Watkins, 2006). Previous studies showed that the quadriceps increase anterior tibial translation

78 and hence ACL strain, while the hamstrings restraining anterior tibial translation and reducing ACL

79 strain (Myer et al., 2005; Podraza and White, 2010). This factor is especially important for female

80 athletes, who are more prone to present ACL injury (Larruskain et al., 2018). 
81 In this context, higher values for hamstrings and quadriceps strength balance ratio has been suggested

82 to be associated with better performance (Trzaskoma et al., 1995) and with a lower risk injury, such

83 as ACL rupture (Cheung et al., 2012). Traditionally, the strength balance ratios for the knee joint has

84 been measured with peak torque values for hamstrings and quadriceps muscles, which represents a

85 single maximum torque values observed in the torque-angle curve at a predetermined velocity. This

86 ratio has been assessed between concentric hamstrings peak torque to concentric quadriceps peak

87 torque (Dvir et al., 1989), and it has been called as conventional strength balance ratio. Previous

88 studies suggest that this ratio should be 0.6 (Hewett et al., 1999, 2008; Jenkins et al., 2013). On the

89 other hand, actual literature remains controversial about the predictive role of these peak torque

90 strength ratios to predict ligament injuries (Bennell et al., 1998; Kannus and Järvinen, 1990; Kim and

91 Hong, 2011; Myer et al., 2009; Sharir et al., 2016), and this controversy may be attributed to the way

92 how the strength balance ratio has been measured. The ratio between antagonist muscles peak torque

93 has been criticized because the muscles peak torque does not occur at the same angle of the range of

94 motion (Eustace et al., 2017). Peak torque of extensor muscles has been reported $\sim 70^{\circ}$ of range of

95 motion (from full extension), and peak torque of flexor muscles has been reported $\sim 30^{\circ}$ (Andrade et

96 al., 2012; Coombs and Garbutt, 2002; Eustace et al., 2017). As consequence, besides hamstrings to

97 quadriceps peak torque ratios, other strength balance index has been advocated, as antagonists'

98 muscles torque ratio of the same angle specific torque (Eustace et al., 2017). Hamstring to quadriceps

99 torque ratio, near to full extension, such as at $30^{\circ}$ has been suggested as a better way to evaluate the

100 knee stability and the knee injury risk factor, considering the high knee injuries at extended knee

101 joint angles (Boden et al., 2000; Eustace et al., 2017; Hewett and Myer, 2011; Higashihara et al.,

102 2015; Olsen et al., 2004).

103 While, bilateral strength deficit and angle-specific measures of isokinetic strength have been assessed

104 in male soccer players presenting different years of practicing (Cohen et al., 2015; El-Ashker et al., 
105 2017; Evangelidis et al., 2015), there are few data for female soccer players athletes. The knowledge

106 of the female strength profile is very important once the number of female soccer player are

107 increasing and female athletes presented higher knee injuries, such as ACL injury, than the male

108 athletes (Hägglund and Waldén, 2016; Larruskain et al., 2018). Moreover, previous data suggested

109 that there are a significant difference in hamstrings to quadriceps torque ratio between sexes

110 (Andrade et al., 2012; Hewett et al., 2008; Hughes and Watkins, 2006); therefore, the existing that

111 available for male athletes cannot be used for female athletes .

112 Thus, the aim of the present study was to evaluate and compare peak torque values, bilateral strength

113 deficit, hamstrings to quadriceps peak torque ratio and hamstrings to quadriceps angle-specific ratio

114 in female soccer players from 11 to 18 years old. We hypothesized that the older female soccer

115 players will present higher strength values for flexor and extensor muscles than the younger, but the

116 balance ratios will not change with the training years. Muscle asymmetries will be expected in the

117 younger group, because they have a short training experience.

118

119

120

121

122

123

124 


\section{METHODS}

\section{Participants}

128 Ninety-three female soccer players voluntarily participated in this study and were divided into groups

129 from three age groups: Under 13 (U13), U15 and U18. The participants were recruited from the female

130 soccer team of the Olympic Training and Research Center (São Paulo, Brazil) and had participated in

131 events at national level, between 2016 and 2018. The athletes were invited through contact with the

132 coach. Athletes were required to be engaged in a soccer training routine with a frequency of three to

133 four times a week, two or three hours per day, for at least two years. And also, strength training two

134 times a week, one hour per day.

135 Athletes who suffered a lower limb injury in the last six months were excluded from the study. On the

136 day of the isokinetic muscle evaluation, the participants were free of pain or discomfort. The physical

137 characteristics (i.e. age, weight, height and BMI) of the participants are summarized in Table 1

138 After receiving instructions regarding the experimental procedures, their possible risks and benefits, as

139 well as the objectives and justification of the research, the parents or guardians (for those athletes under

14018 years old) and athletes signed the consent form. All the experimental procedures of the study were

141 approved by a proper research ethics committee (approval number: 80282817.0.0000.5505) and meets

142 the ethical standards of the Declaration of Helsinki.

143 Table 1 about here

144 Experimental procedures

145 Before the experimental procedures were undertaken, each athlete visited our laboratory to receive 146 instructions about the study and to answer a questionnaire about the physical training habits and injury

147 history. If the athlete attends the inclusion criteria and the parents or guardians (for those athletes under 
18 years old) and athletes signed the consent form of the study. Athletes weight was measured using a

149 portable scale previously calibrated to the proximal $0.1 \mathrm{~kg}$, and height has measured using a stadiometer

150 calibrated to $0.1 \mathrm{~cm}$ (Filizola, São Paulo, Brasil). After that, isokinetic muscle strength evaluation was

151 performed.

152

153 The isokinetic muscle evaluation was performed using the isokinetic dynamometer, Biodex System 3

154 (Biodex Medical System, Shirley, NY, USA). Prior to the test, participants performed five-minute

155 warm up by going up and down a ladder, and a light dynamic muscle stretching of lower limb muscles.

156 This kind of stretching generates minimum impairment to muscle strength (Mascarin et al., 2015). The

157 adopted position was seated (approximately $90^{\circ}$ hip flexion) with trunk, hip and thigh fixed with bands

158 to minimize body movements and isolate knee joint movements. The distal fixation was placed two

159 centimeters above the lateral malleolus of the fibula. The axis of the isokinetic dynamometer was

160 aligned with the lateral epicondyle of the femur. The limit of the range of motion was determined by

161 goniometry. Full extension was considered as $0^{\circ}$. Movement started at $90^{\circ}$ of knee flexion to full

162 extension. Gravity correction was done for each lower limb before the test to reduce the risks of

163 imprecision.

165 The test started with the dominant lower limb, determined by asking the participants which limb they

166 preferred to use when kicking a ball. Both lower limbs were evaluated. All volunteers were instructed

167 verbally about the procedure and received standardized incentives during the test. The test consisted

168 of five maximal concentric repetitions of knee flexion and extension at angular speeds of $60^{\circ} . \mathrm{s}^{-1}$ and

$169240^{\circ} \cdot \mathrm{s}^{-1}$. Among the angular speed tested there was an interval of sixty seconds and between the limbs

170 tested there was an interval of three minutes. For familiarization, the participants were given standard

171 verbal instructions regarding the procedures and allowed several submaximal practice attempts (de 
172 Lira et al., 2017). The following variables were measured: peak torque $(\mathrm{Nm})$ at $60^{\circ} \cdot \mathrm{s}^{-1}$ and $240^{\circ} \cdot \mathrm{s}^{-1}$,

173 total work $(\mathrm{J})$ at $60^{\circ} \cdot \mathrm{s}^{-1}$ and $240^{\circ} . \mathrm{s}^{-1}$, torque at $30^{\circ}$ (torque measured at 30 degrees of range of motion)

$174(\mathrm{Nm})$ at $60^{\circ} . \mathrm{s}^{-1}$, and average power (W) at $240^{\circ} . \mathrm{s}^{-1}$ of the knee flexor and extensor muscles. The

175 conventional strength balance ratios (peak torque of the flexor muscles / peak torque of the extensor

176 muscles) and the angle-specific balance ratio (torque at $30^{\circ}$ of the flexor muscles / torque at $30^{\circ}$ of the

177 extensor muscles). Limb symmetry indexes (LSI) were calculated by the following equation.

$$
L S I=\left[\frac{(\text { dominant limb data }- \text { non dominant limb data })}{\text { dominant limb data }}\right] X 100
$$

180 Statistical analyses

181 Statistical analyses were performed using the Statistica software (Statsoft, Inc., version 6.0 for

182 Windows, USA). Data were expressed as mean \pm standard deviation (SD). Variable distribution was

183 tested by the Kolmogorov-Smirnov test, and variability by the Levene test. Two-way ANOVA was

184 used to assess group (U13 vs. U15 vs. U18) and side (dominant vs. non-dominant) differences in the

185 isokinetic parameters. When significant group-by-side interactions were present, Tukey's post-hoc

186 procedures were used to identify the specific differences. In the absence of interactions, only the main

187 effects were analyzed. In order to compare conventional strength balance ratio with recommended

188 literature value of $60 \%$, a single sample t-test was conducted. Statistical significance was set at an alpha

189 of .05. 


\section{RESULTS}

195 There were seventy five percent of right-handed athletes in U13, eighty three percent in U15 and

196 seventy two percent in U18. Athletes in U15 presented significantly higher values for age, weight,

197 height and BMI than U13 (Table 1). However, only age was different between U15 and U18 (Table 198 1).

199 In the comparison of the results obtained in the isokinetic muscle evaluation of the dominant and non200 dominant limbs, it was observed that U13 athletes had significantly higher total work of the extensor 201 muscles $\left(240^{\circ} . \mathrm{s}^{-1}\right)(\mathrm{P}=.02,8 \%)$ of the dominant side and U15 athletes presented significantly higher 202 peak torque of the flexor muscles $\left(240^{\circ} . \mathrm{s}^{-1}\right)(\mathrm{P}=.02,6 \%)$ of the dominant side when compared with 203 non-dominant side. U18 athletes had no significant contralateral difference (Table 2).

204 When comparing the age groups U13, U15 and U18, a significant increase ( $>$ > .05) from age group 205 U13 to U15 was observed in all measured parameters of knee extensor muscles, for both lower limbs. 206 Age groups U15 to U18 did not significantly differ (Table 2). It is also observed that the torque values 207 measured at $30^{\circ}$ are significantly lower than the peak torque values $(\mathrm{p}<.05)$ when comparing the 208 extensor muscles of the same limb and of the same age group. The percentage values of this difference 209 were between 65 and $52 \%$.

210 Table 2 about here

211 Comparing the knee flexor muscles, the U15 athletes presented a significant difference of the peak

212 torque values at $240 \mathrm{deg} \cdot \mathrm{s}^{-1}$ between dominant and non-dominant $\operatorname{limbs}{ }^{1}(\mathrm{P}=.02,6 \%)$. The U13 and 213 U18 athletes showed no significant contralateral differences (Table 3).

214 When comparing the different age groups, it was also possible to observe a significant increase $(\mathrm{p}<.05)$ 215 from age group U13 to U15 in all parameters measured from the knee flexor muscles, both dominant 
216 and non-dominant. Among U15 and U18 athletes there was no significant difference in the parameters

217 evaluated for the knee flexor muscles (Table 3). It is also observed that the torque values measured at

$21830^{\circ}$ are significantly lower than the peak torque values $(p<.05)$ when comparing the flexor muscles of

219 the same limb and the same age group. The percentage values of this difference were between 16 and $220 \quad 33 \%$.

221 Table 3 about here

222 The conventional strength balance ratios (peak torque of the flexor muscles / peak torque of the 223 extensor muscles) and the angle-specific balance ratio (torque at $30^{\circ}$ of the flexor muscles / torque at $22430^{\circ}$ of the extensor muscles) of U13, U15 and U18 did not present significant contralateral differences 225 nor significant differences among age groups. The three age groups presented significantly lower 226 values of conventional muscle balance $(p<.05)$ than the reference value determined in the literature 227 (60\%) (Table 4).

$228 \quad$ Table 4 about here 
240 The aim of the present study was to evaluate and compare between different female soccer players age

241 groups the knee muscular strength, side-to-side strength differences, and the strength balance ratios.

242 We also aimed to compare peak torque values with torque values assessed at $30^{\circ}$. The main results of

243 the study were, that despite the peak torque values being higher in U15 age group than in U13, the knee

244 balance ratios maintained stable between age groups assessed. Another interesting data is that the

245 conventional balance ratio was lower than the literature recommendation $(60 \%)$ for all the age groups,

246 and there were no important muscular asymmetries in any age group.

247 The parameters of peak torque (the highest torque value developed during the range of motion), total

248 work (the integral of the torque-angle curve) and average power (the time expended to perform the

249 total work) are often used to evaluate the isokinetic muscular performance of a given population (Dvir,

250 2014). In the present study, we observed that the U15 athletes presented values of torque, work and

251 power of the flexor and extensor muscles significantly higher than the U13 age group; while there were

252 no significant differences between the U18 and U15 athletes. These results were expected since muscle

253 adaptations are more evident in younger athletes and in the early years of training, and then become

254 less evident (Fousekis et al., 2010). Moreover, the athletes were also growing up between U13 and

255 U15 (U15 presented higher values for height and body mass than U13), which also contribute to the

256 higher strength values observed in U15. Our data was according to previous data reported for male

257 soccer players. Kellis et al. (2000) demonstrated that body mass and age were strongly associated with

258 concentric isokinetic thigh muscles strength, and they are the main predictor variables for concentric

259 isokinetic strength. Between U15 and U18, there were no significant difference in weight and height

260 values, then this may be the reason for the lack of isokinetic muscular strength difference. BMI was

261 higher in U15 than in U13 athletes. Previous literature data have demonstrated that higher BMI were

262 associated with lower muscular strength (Bonney et al., 2018). This apparent contradictory data can 
be explained because previous study compared people with normal BMI with overweight people,

264 which is different in our study. Athletes in U15 were classified as normal weight and the athletes in

265 U13 were classified as underweight, which may be harmful for strength development.

266 Regarding the asymmetry of muscular strength, we observed that the U18 athletes did not show any 267 asymmetry, age group U15 presented asymmetry of flexors peak torque at $240^{\circ} . \mathrm{s}^{-1}$ and, age group U13,

268 of extensors total work at $240^{\circ} \cdot \mathrm{s}^{-1}$. In fact, we can expect more evident asymmetries of strength in

269 younger athletes than the more experienced ones, since the younger ones do not present sufficient

270 maturity of the kinetic and neuromuscular patterns to deal with the asymmetry present in the sport

271 (Fousekis et al., 2010). On the other hand, although these contralateral differences have been identified,

272 it is worth noting that in percentage values, these differences are less than $10 \%$, which is within a limit

273 of normality determined in the literature (Daneshjoo et al., 2013). Thus, although there were significant

274 contralateral differences, we can consider that they are not important from the clinical point of view.

275 Another interesting point to note is that despite soccer is an asymmetrical sport, the whole group

276 evaluated did not present significant muscular asymmetry, contrary to the initial hypothesis of the 277 study.

278 The conventional muscle balance ratios were not different between the age groups, indicating that there

279 is a strengthening of the same magnitude of both muscle groups over the years of sports practice.

280 Moreover, conventional muscle balance ratios presented by the dominant and non-dominant limbs of

281 all age groups were lower than $60 \%$, which is the lower limit recommended by the literature (Hewett

282 et al., 1999, 2008; Jenkins et al., 2013). Andrade et al. (2012) studied men and women soccer players.

283 The authors also found low ratios for women ( $54 \pm 11 \%)$, but not for men $(66 \pm 12 \%)$. Values below

284 this recommendation in the literature were also found by (Vargas et al., 2019) for women soccer players

285 and by Lira et al. (2017) for male soccer, futsal and beach soccer players. It is possible that the lower

286 conventional ratio presented by soccer player athletes was associated with ACL injury, which is one 
287 of the most frequent severe knee injuries in this population (Chomiak et al., 2000). However, 288 prospective studies should be performed to elucidate this question.

289 In addition to the conventional balance ratio, angle-specific balance ratio at $30^{\circ}$ also was studied. The 290 assessment of muscle balance at the $30^{\circ}$ angle is suggested because the greatest occurrence of knee 291 injuries, such as ACL injury, or hamstrings injuries, occurs at the end of the range of motion (Baldon 292 et al., 2011; Eustace et al., 2017).

293 In the same way as the conventional balance ratio, the angle-specific balance ratio was also not different 294 between the age groups nor between dominant and non-dominant limbs of the same age group. The 295 values of angle-specific balance ratio were significantly higher than those observed for the 296 conventional ratio. The torque curve of the extensor muscles has a rather different morphology than 297 the hamstrings muscles torque curve (El-Ashker et al., 2017). In the present study, it is observed that 298 the torque value of knee extensor muscles assessed at $30^{\circ}$ is much lower than the peak torque value of 299 the same muscles (52\% to $65 \%$, depending on the age group). On the other hand, the torque value of 300 knee flexor muscles assessed at $30^{\circ}$ is not so different from the peak torque values of the same muscles 301 (16 to $33 \%$ depending on the age group). As in the $30^{\circ}$ evaluation, the strength of extensors muscles 302 decreases much more in relation to the flexor's strength, the ratio between both becomes higher and, 303 in most cases, exceeds $100 \%$. Numerous studies have shown that the knee extensor muscles action 304 increase anterior tibial translation (particularly with the knee close to full extension) and hence ACL 305 strain, on the other hand, the knee flexor muscles are responsible to restrain anterior tibial translation 306 and reduce ACL strain. Therefore, it is possible that a higher strength balance ratio at $30^{\circ}$ (higher than 307 100\%) should be important to stabilize the knee joint avoiding ACL strain. However, prospective 308 studies also should be done in order to establish the role of angle-specific balance ratios. 
309 One potential limitation of the study is the lack of eccentric torque evaluation, which makes it

310 impossible to study functional strength balance ratio, the ratio between eccentric action of flexor

311 muscles and concentric action of extensor muscles. The possibility to evaluate the functional ratio

312 would contribute to a better understanding of the knee joint dynamic instability. Thus, further studies

313 with knee muscles eccentric evaluation are needed.

\section{Conclusion}

315 The present study demonstrated that young female soccer players from 11 to 18 years old, despite of

316 the asymmetric characteristic of the sports activities, the dominant and non-dominant limbs

317 demonstrated symmetrical strength in the knee joint muscles. Knee conventional balance ratio also

318 demonstrated no differences between dominant and non-dominant limbs and age groups. On the other

319 hand, all age groups presented conventional balance ratio lower than the literature recommendation,

320 evidencing a flexor muscles insufficiency. The strength balance ratio at $30^{\circ}$ also presented no difference

321 between dominant and non-dominant limbs and age groups. This data from female soccer players can

322 be compared to other athletes to help determine individual weaknesses, strengths, and imbalances, and

323 may be useful for designing training or rehabilitation programs. Finally, these results can be used as

324 normative data regarding isokinetic profiles in female young soccer players athletes. 


\section{Acknowledgments}

334 We would like to thank all of the participants who volunteered their time to participate in the study and the Olympic Training and Research Center - COTP (São Paulo, Brazil). Rodrigo Luiz Vancini is a productivity fellowship at the Fundação de Amparo à Pesquisa e Inovação do Espírito Santo (FAPES) agency (Edital No 18/2018 - Bolsa Pesquisador Capixaba).

\section{Author Contributions Statement}

339 MA and MJ conceived the original idea and planned the experiments. All authors provided critical feedback and helped shape the research, analysis and manuscript. MJ carried out the experiment with support from AS. MA, CL, RLV, TR, PTN and BK planned and carried out the statistical analyses. All authors discussed the results and contributed to the final manuscript. MA took the lead in writing the manuscript with support from CL, RLV, TR, PTN and BK.

\section{Conflict of Interest Statement}

345 The authors declare that the research was conducted in the absence of any commercial or financial relationships that could be construed as a potential conflict of interest.

\section{7}

348

\section{Data Availability Statement}

The anonymized data used to support the findings of this study are available from the corresponding author upon request.

\section{Funding}

No funding to declare.

\section{Contribution to the Field Statement}

The muscular strength profiles of athletes involved with different sports modalities can provide a basis for understanding muscular adaptations due to specific training, the requirements necessary for sport success, and injury risk management. Once a high muscular demand of hamstring and quadriceps muscle are present in soccer players, several previous studies have studied isokinetic strength profile for male athletes providing valuable information for them, but less is known for female soccer players. Therefore, it is unclear how soccer affects side-to-side difference and strength balance ratios in female adolescents' athletes. Characterization of these isokinetic knee parameters may contribute to a better understanding of muscular adaptation generated in female soccer players, moreover, reference values can be helpful to direct strength training and rehabilitation processes. 


\section{REFERENCES}

368 Andrade, M. D. S., De Lira, C. A. B., Koffes, F. D. C., Mascarin, N. C., Benedito-Silva, A. A., and Da Silva, A. C. (2012). Isokinetic hamstrings-to-quadriceps peak torque ratio: The influence of sport modality, gender, and angular velocity. J. Sports Sci. 30, 547-553. doi:10.1080/02640414.2011.644249.

Arnason, A., Sigurdsson, S. B., Gudmundsson, A., Holme, I., Engebretsen, L., and Bahr, R. (2004). Risk Factors for Injuries in Football. Am. J. Sports Med. 32, 5-16. doi:10.1177/0363546503258912.

Baldon, R. de M., Lobato, D. F. M., Carvalho, L. P., Wun, P. Y. L., and Serrão, F. V. (2011). Diferenças biomecânicas entre os gêneros e sua importância nas lesões do joelho. Fisioter. em Mov. 24, 157-166. doi:10.1590/S0103-51502011000100018.

Bennell, K., Wajswelner, H., Lew, P., Schall-Riaucour, A., Leslie, S., Plant, D., et al. (1998). Isokinetic strength testing does not predict hamstring injury in Australian Rules footballers. $\mathrm{Br}$. J. Sports Med. 32, 309-14. doi:10.1136/bjsm.32.4.309.

Boden, B. P., Dean, G. S., Feagin, J. A., and Garrett, W. E. (2000). Mechanisms of anterior cruciate ligament injury. Orthopedics 23, 573-8.

Bonney, E., Ferguson, G., Smits-Engelsman. B. (2018). Relationship between Body Mass Index, Cardiorespiratory and Musculoskeletal Fitness among South African Adolescent Girls. Int J Environ Res Public Health. 28;15(6).

Cheung, R. T. H., Smith, A. W., and Wong, D. P. (2012). H:q ratios and bilateral leg strength in college field and court sports players. J. Hum. Kinet. 33, 63-71. doi:10.2478/v10078-0120045-1.

Chomiak, J., Junge, A., Peterson, L., and Dvorak, J. (2000). Severe injuries in football players. Influencing factors. Am. J. Sports Med. 28, S58-68.

Cohen, D. D., Zhao, B., Okwera, B., Matthews, M. J., and Delextrat, A. (2015). Angle-Specific Eccentric Hamstring Fatigue After Simulated Soccer. Int. J. Sports Physiol. Perform. 10, 325331. doi:10.1123/ijspp.2014-0088.

Coombs, R., and Garbutt, G. (2002). Developments in the use of the hamstring/quadriceps ratio for the assessment of muscle balance. J. Sports Sci. Med. 1, 56-62.

Daneshjoo, A., Rahnama, N., Mokhtar, A. H., and Yusof, A. (2013). Bilateral and Unilateral Asymmetries of Isokinetic Strength and Flexibility in Male Young Professional Soccer Players. J. Hum. Kinet. 36, 45-53. doi:10.2478/hukin-2013-0005.

de Lira, C. A. B., Mascarin, N. C., Vargas, V. Z., Vancini, R. L., and Andrade, M. S. (2017). Isokinetic knee muscle strength profile in brazilian male soccer, futsal, and beach soccer players: a cross-sectional study. Int. J. Sports Phys. Ther. 12, 1103-1110.

Dvir, Z. (2014). Relevant, less relevant and irrelevant isokinetic strength test parameters: Some critical comments. Mov. Sport Sci. - Sci. Mot., 15-21. doi:10.1051/sm/2013088. 
404

405

406

407

408

409

410

411

412

413

414

415

416

417

418

419

420

421

422

423

424

425

426

427

428

429

430

431

432

433

434

435

436

437

438

439

440

Dvir, Z., Eger, G., Halperin, N., and Shklar, A. (1989). Thigh muscle activity and anterior cruciate ligament insufficiency. Clin. Biomech. 4, 87-91. doi:10.1016/0268-0033(89)90044-2.

El-Ashker, S., Carson, B. P., Ayala, F., and De Ste Croix, M. (2017). Sex-related differences in jointangle-specific functional hamstring-to-quadriceps strength ratios. Knee Surgery, Sport. Traumatol. Arthrosc. 25, 949-957. doi:10.1007/s00167-015-3684-7.

Eustace, S. J., Page, R. M., and Greig, M. (2017). Contemporary approaches to isokinetic strength assessments in professional football players. Sci. Med. Footb. 1, 251-257. doi:10.1080/24733938.2017.1371851.

Evangelidis, P. E., Pain, M. T. G., and Folland, J. (2015). Angle-specific hamstring-to-quadriceps ratio: A comparison of football players and recreationally active males. J. Sports Sci. 33, 309319. doi:10.1080/02640414.2014.942680.

Fousekis, K., Tsepis, E., and Vagenas, G. (2010). Lower limb strength in professional soccer players: profile, asymmetry, and training age. J. Sports Sci. Med. 9, 364-73.

Hägglund, M., and Waldén, M. (2016). Risk factors for acute knee injury in female youth football. Knee Surgery, Sport. Traumatol. Arthrosc. 24, 737-746. doi:10.1007/s00167-015-3922-z.

Hewett, T. E., Lindenfeld, T. N., Riccobene, J. V., and Noyes, F. R. (1999). The Effect of Neuromuscular Training on the Incidence of Knee Injury in Female Athletes. Am. J. Sports Med. 27, 699-706. doi:10.1177/03635465990270060301.

Hewett, T. E., and Myer, G. D. (2011). The Mechanistic Connection between the Trunk, Knee, and ACL Injury. Exerc. Sport Sci. Rev. 39, 1. doi:10.1097/JES.0b013e3182297439.

Hewett, T. E., Myer, G. D., and Zazulak, B. T. (2008). Hamstrings to quadriceps peak torque ratios diverge between sexes with increasing isokinetic angular velocity. J. Sci. Med. Sport 11, 452459. doi:10.1016/j.jsams.2007.04.009.

Higashihara, A., Nagano, Y., Ono, T., and Fukubayashi, T. (2015). Differences in activation properties of the hamstring muscles during overground sprinting. Gait Posture 42, 360-364. doi:10.1016/j.gaitpost.2015.07.002.

Hughes, G., and Watkins, J. (2006). A Risk-Factor Model for Anterior Cruciate Ligament Injury. Sport. Med. 36, 411-428. doi:10.2165/00007256-200636050-00004.

Jenkins, N. D. M., Hawkey, M. J., Costa, P. B., Fiddler, R. E., Thompson, B. J., Ryan, E. D., et al. (2013). Functional hamstrings: quadriceps ratios in elite women's soccer players. J. Sports Sci. 31, 612-617. doi:10.1080/02640414.2012.742958.

Kannus, P., and Järvinen, M. (1990). Knee flexor/extensor strength ratio in follow-up of acute knee distortion injuries. Arch. Phys. Med. Rehabil. 71, 38-41.

Kellis, S., Kellis, E., Manou, V., Gerodimos, V. (2000). Prediction of knee extensor and flexor isokinetic strength in young male soccer players. J Orthop Sports Phys Ther. 30(11):693-701.

Kim, D., and Hong, J. (2011). Hamstring to quadriceps strength ratio and noncontact leg injuries: A 
prospective study during one season. Isokinet. Exerc. Sci. 19, 1-6. doi:10.3233/IES-2011-0406.

442

443

444

445

446

447

448

449

450

451

452

453

454

455

456

457

458

459

460

461

462

463

464

465

466

467

468

469

470

471

472

473

474

475

476

477

Knapik, J. J., Bauman, C. L., Jones, B. H., Harris, J. M., and Vaughan, L. (1991). Preseason strength and flexibility imbalances associated with athletic injuries in female collegiate athletes. Am. J. Sports Med. 19, 76-81. doi:10.1177/036354659101900113.

Kotzamanidis, C., Chatzopoulos, D., Michailidis, C., Papaiakovou, G., and Patikas, D. (2005). The Effect of a Combined High-Intensity Strength and Speed Training Program on the Running and Jumping Ability of Soccer Players. J. Strength Cond. Res. 19, 369. doi:10.1519/R-14944.1.

Larruskain, J., Lekue, J. A., Diaz, N., Odriozola, A., and Gil, S. M. (2018). A comparison of injuries in elite male and female football players: A five-season prospective study. Scand. J. Med. Sci. Sports 28, 237-245. doi:10.1111/sms.12860.

Mascarin, N. C., Vancini, R. L., Lira, C. A. B., and Andrade, M. S. (2015). Stretch-Induced Reductions in Throwing Performance Are Attenuated by Warm-up Before Exercise. J. Strength Cond. Res. 29, 1393-1398. doi:10.1519/JSC.0000000000000752.

Myer, G. D., Ford, K. R., Barber Foss, K. D., Liu, C., Nick, T. G., and Hewett, T. E. (2009). The Relationship of Hamstrings and Quadriceps Strength to Anterior Cruciate Ligament Injury in Female Athletes. Clin. J. Sport Med. 19, 3-8. doi:10.1097/JSM.0b013e318190bddb.

Myer, G. D., Ford, K. R., Palumbo, J. P., and Hewett, T. E. (2005). Neuromuscular Training Improves Performance and Lower-Extremity Biomechanics in Female Athletes. J. Strength Cond. Res. 19, 51. doi:10.1519/13643.1.

Olsen, O.-E., Myklebust, G., Engebretsen, L., and Bahr, R. (2004). Injury Mechanisms for Anterior Cruciate Ligament Injuries in Team Handball. Am. J. Sports Med. 32, 1002-1012. doi:10.1177/0363546503261724.

Podraza, J. T., and White, S. C. (2010). Effect of knee flexion angle on ground reaction forces, knee moments and muscle co-contraction during an impact-like deceleration landing: Implications for the non-contact mechanism of ACL injury. Knee 17, 291-295. doi:10.1016/j.knee.2010.02.013.

Reilly, T., and Thomas, V. (1975). A motion analysis of work rate in different positional roles in professional football match play. J. Hum. Mov. Stud. 2, 87-97.

Rösch, D., Hodgson, R., Peterson, T. L., Graf-Baumann, T., Junge, A., Chomiak, J., et al. (2000). Assessment and evaluation of football performance. Am. J. Sports Med. 28, S29-39.

Sharir, R., Rafeeuddin, R., Staes, F., Dingenen, B., George, K., Vanrenterghem, J., et al. (2016). Mapping current research trends on anterior cruciate ligament injury risk against the existing evidence: In vivo biomechanical risk factors. Clin. Biomech. 37, 34-43. doi:10.1016/j.clinbiomech.2016.05.017.

Siqueira, C. M., Pelegrini, F. R. M. M., Fontana, M. F., and Greve, J. M. D. (2002). Isokinetic dynamometry of knee flexors and extensors: comparative study among non-athletes, jumper athletes and runner athletes. Rev. Hosp. Clin. Fac. Med. Sao. Paulo. 57, 19-24. 
Stolen, T., Chamari, K., Castagna, C., and Wisloff, U. (2005). Physiology of Soccer. Sport. Med. 35, 501-536. doi:10.2165/00007256-200535060-00004.

Trzaskoma, Z., Wit, A., and Eliasz, J. (1995). Comparison of three laboratory tests of short duration with respect to the mechanical power output by lower limbs of athletes. Biol. Sport 13, 61-70.

Vargas, V. Z., Motta, C., Peres, B., Vancini, R. L., Andre Barbosa De Lira, C., and Andrade, M. S. (2019). Knee isokinetic muscle strength and balance ratio in female soccer players of different age groups: a cross-sectional study. Phys. Sportsmed., 1-5. doi:10.1080/00913847.2019.1642808.

Voutselas, V., Papanikolaou, Z., Soulas, D., and Famisis, K. (2007). Years of Training and Hamstring-Quadriceps Ratio of Soccer Players. Psychol. Rep. 101, 899-906. doi:10.2466/pr0.101.3.899-906. 
Table 1. Physical characteristics of athletes of age groups U13, U15 and U18.

\begin{tabular}{lccc} 
& $\begin{array}{c}\mathbf{U 1 3} \\
\mathbf{n}=\mathbf{3 5}\end{array}$ & $\mathbf{U 1 5}$ & $\mathbf{U 1 8}$ \\
$\mathbf{n = 3 6}$ & $\mathbf{3}=\mathbf{2 2}$ \\
\hline Age (years) & $11.83 \pm 0, .7$ & $13.72 \pm 0.51^{*}$ & $16.10 \pm 0.89 \#$ \\
& $(11.00-13.00)$ & $(13.00-15.00)$ & $(15.00-18.00)$ \\
Body mass $(\mathbf{k g})$ & $40.75 \pm 7.54$ & $53.95 \pm 7.42^{*}$ & $55.66 \pm 8.96$ \\
& $(29.00-65.00)$ & $(40.00-70.90)$ & $(36.90-69.00)$ \\
Height $(\mathbf{m})$ & $1.51 \pm 0.06$ & $1.60 \pm 0.05^{*}$ & $1.60 \pm 0.07$ \\
& $(1.36-1.67)$ & $(1.49-1.77)$ & $(1.47-1.71)$ \\
BMI $\left(\mathbf{k g} / \mathbf{m}^{2}\right)$ & $17.7 \pm 2.6$ & $20.7 \pm 2.3^{*}$ & $21.7 \pm 3.4$ \\
& $(14.3-27.3)$ & $(16.3-25.5)$ & $(15.5-29.1)$ \\
\hline
\end{tabular}

509 Mean \pm SD (min - max).

$510 \mathrm{SD}$ (standard deviation), min (minimum), max (maximum)

$511 * \mathrm{P}<.05(\mathrm{U} 15 \neq \mathrm{U} 13)$

$512 \# \mathrm{P}<.05(\mathrm{U} 18 \neq \mathrm{U} 15)$

513

514

515

516

517

518

519

520

521

522

523

524

525

526 
527 Table 2. Isokinetic muscle evaluation of dominant and non-dominant knee extensor muscles, age groups U13, U15 and U18.

\begin{tabular}{|c|c|c|c|c|c|c|}
\hline & \multicolumn{2}{|c|}{$\begin{array}{c}\text { U13 } \\
n=35\end{array}$} & \multicolumn{2}{|c|}{$\begin{array}{c}\mathrm{U} 15 \\
\mathrm{n}=36\end{array}$} & \multicolumn{2}{|c|}{$\begin{array}{c}\mathrm{U} 18 \\
\mathrm{n}=22\end{array}$} \\
\hline & Dominant & Non-dominant & Dominant & Non-dominant & Dominant & Non-dominant \\
\hline \multirow{2}{*}{$\begin{array}{c}\text { PT } 60^{\circ} . s^{-1} \\
(\mathrm{~N}-\mathrm{M})\end{array}$} & $91.1 \pm 19.4$ & $88.5 \pm 20.3$ & $137.6 \pm 21.7 \#$ & $135.9 \pm 30.0 \#$ & $146.5 \pm 28.3$ & $145.2 \pm 32.0$ \\
\hline & $(57.1-124.7)$ & $(52.2-133.5)$ & $(99.7-175.0)$ & $(58.2-187.7)$ & $(77.3-184.0)$ & $(79.0-211.8)$ \\
\hline \multirow{2}{*}{$\begin{array}{cc}\text { TW } & 60 \\
{ }^{\circ} \cdot \mathbf{s}^{-1} & (J)\end{array}$} & $92.9 \pm 20.8$ & $90.4 \pm 21.7$ & $159.4 \pm 31.3 \#$ & $154.2 \pm 33.2 \#$ & $170.0 \pm 40.0$ & $173.3 \pm 40.4$ \\
\hline & $(57.1-149.3)$ & $(52.2-133.5)$ & $(98.8-216.1)$ & $(90.7-224.1)$ & $(93.5-250.9)$ & $(102.3-243.2)$ \\
\hline \multirow{2}{*}{$\begin{array}{c}\text { PT } 240 \\
\quad{ }^{\circ} \mathbf{s}^{-1} \\
(\mathbf{N}-M)\end{array}$} & $58.2 \pm 18.2$ & $59.6 \pm 22.0$ & $82.0 \pm 13.0 \#$ & $79.7 \pm 15.2 \#$ & $88.3 \pm 17.2$ & $88.1 \pm 16.9$ \\
\hline & $(32.9-138.6)$ & $(32.8-167.1)$ & $(54.0-104.4)$ & $(36.8-108.1)$ & $(57.3-116.8)$ & $(59.9-112.0)$ \\
\hline \multirow{2}{*}{ 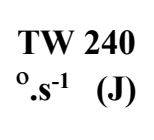 } & $69.9 \pm 16.6$ & $76.1 \pm 19.5^{*}$ & $107.0 \pm 38.7 \#$ & $106.3 \pm 18.6 \#$ & $118.8 \pm 26.5$ & $117.5 \pm 25.1$ \\
\hline & $(38.8-113.6)$ & $(28.1-112.8)$ & $(105.3-245.1)$ & $(68.7-138.5)$ & $(67.8-159.9)$ & $(72.5-158.4)$ \\
\hline \multirow{2}{*}{$\begin{array}{l}\text { AVG P } \\
240^{\circ} \cdot s^{-1} \\
\text { (Watts) }\end{array}$} & $114.6 \pm 31.5$ & $123.4 \pm 32.0$ & $181.3 \pm 36.0 \#$ & $181.2 \pm 36.2 \#$ & $205.6 \pm 48.0$ & $204.7 \pm 41.9$ \\
\hline & $(50.4-13.5)$ & $(66.6-199.6)$ & $(245.1-105.3)$ & $(96.2-244.0)$ & $(117.8-282.0)$ & $(113.2-257.7)$ \\
\hline $\mathrm{T}^{\circ} 0^{\circ} 60$ & $37.4 \pm 15.8 \&$ & $31.8 \pm 11.8 \&$ & $60.4 \pm 15.9 \# \&$ & $56.7 \pm 19.5 \# \&$ & $71.4 \pm 21.0 \&$ & $67.2 \pm 25.5 \&$ \\
\hline$(\mathrm{N}-\mathrm{M})$ & $(13.2-93.7)$ & $(11.8-56.4)$ & $(28.9-85.1)$ & $(26.3-94.5)$ & $(31.3-96.7)$ & $(23.7-115.8)$ \\
\hline
\end{tabular}

$528 * \mathrm{P}<.05$ (dominant $\neq$ non-dominant).

$529 \# \mathrm{P}<.05(\mathrm{U} 15 \neq \mathrm{U} 13$ - same member)

$530 \& \mathrm{P}<.05\left(\mathrm{~T} 30^{\mathrm{o}} \neq \mathrm{PT} 60^{\circ} . \mathrm{s}^{-1}\right)$

531 Mean \pm SD (min - max).

532 SD (standard deviation), min (minimum), max (maximum), PT (peak torque), TW (total work), AVG P (average power), $533 \mathrm{~T} 30^{\circ}$ (torque rated $30^{\circ}$ )

534

535

536

537

538

539

540

541 
542 Table 3. Isokinetic muscle evaluation of dominant and non-dominant knee flexor muscles of age groups U13, U15 and U18.

\begin{tabular}{|c|c|c|c|c|c|c|}
\hline & \multicolumn{2}{|c|}{$\begin{array}{c}\mathbf{U 1 3} \\
\mathrm{n}=35\end{array}$} & \multicolumn{2}{|c|}{$\begin{array}{c}\mathrm{U} 15 \\
\mathrm{n}=36\end{array}$} & \multicolumn{2}{|c|}{$\begin{array}{c}\mathrm{U} 18 \\
\mathrm{n}=\mathbf{2 2}\end{array}$} \\
\hline & Dominant & Non-dominant & Dominant & Non-dominant & Dominant & Non-dominant \\
\hline \multirow{2}{*}{$\begin{array}{c}\mathrm{PT} 60^{\circ} / \mathrm{s} \\
(\mathrm{N}-\mathrm{M})\end{array}$} & $49.4 \pm 12.6$ & $47.7 \pm 12.1$ & $77.4 \pm 13.4 \#$ & $73.9 \pm 13.3 \#$ & $81.8 \pm 16.1$ & $78.8 \pm 16.5$ \\
\hline & $(27.3-76.6)$ & $(26.6-71.1)$ & $(50.2-103.5)$ & $(53.0-105.5)$ & $(47.4-105.5)$ & $(40.4-109.8)$ \\
\hline \multirow{2}{*}{$\begin{array}{c}\text { TW } \\
60^{\circ} / \mathbf{s}(\mathrm{J})\end{array}$} & $59.7 \pm 18.7$ & $59.5 \pm 16.3$ & $97.8 \pm 19.8 \#$ & $95.3 \pm 21.0 \#$ & $105.8 \pm 24.5$ & $99.2 \pm 23.5$ \\
\hline & $(28.3-101.4)$ & $(31.2-95.2)$ & $(60.3-130.5)$ & $(58.4-152.2)$ & $(59.0-151.1)$ & $(50.6-135.3)$ \\
\hline \multirow{2}{*}{$\begin{array}{c}\text { PT } \\
240^{\circ} / \mathrm{s} \\
(\mathrm{N}-\mathrm{M})\end{array}$} & $38.3 \pm 8.1$ & $36.2 \pm 9.6$ & $55.0 \pm 10.1 \#$ & $52.0 \pm 9.0 * \#$ & $59.0 \pm 11.0$ & $55.8 \pm 10.6$ \\
\hline & $(22.0-55.3)$ & $(16.1-59.3)$ & $(38.1-79.2)$ & $(37.8-75.7)$ & $(35.6-74.9)$ & $(37.2-71.8)$ \\
\hline \multirow{2}{*}{$\begin{array}{c}\text { TW } \\
240 \% / \mathrm{s} \\
\text { (J) }\end{array}$} & $43.2 \pm 13.3$ & $43.8 \pm 13.0$ & $68.1 \pm 16.4 \#$ & $66.1 \pm 12.4 \#$ & $75.0 \pm 14.2$ & $71.5 \pm 13.5$ \\
\hline & $(10.1-76.1)$ & $(22.7-69.6)$ & $(33.3-105.6)$ & $(36.7-87.2)$ & $(43.8-99.4)$ & $(48.2-88.7)$ \\
\hline $\begin{array}{c}\text { AVG P } \\
240 \% \text { s } \\
\text { (Watts) }\end{array}$ & $\begin{array}{c}46.1 \pm 16.7 \\
(10.1-101.3)\end{array}$ & $\begin{array}{l}45.8 \pm 16.2 \\
(19.7-99.7)\end{array}$ & $\begin{array}{l}112.7 \pm 30.5 \# \\
(47.2-179.0)\end{array}$ & $\begin{array}{l}108.7 \pm 24.1 \# \\
(56.9-152.7)\end{array}$ & $\begin{array}{l}123.5 \pm 24.7 \\
(65.1-163.0)\end{array}$ & $\begin{array}{c}118.8 \pm 25.3 \\
(70.2-147.9)\end{array}$ \\
\hline $\begin{array}{l}\mathrm{T30}^{\circ} \\
60^{\circ} / \mathrm{s}(\mathrm{N}- \\
\mathrm{M})\end{array}$ & $\begin{array}{l}34.1 \pm 13.8 \& \\
(13.2-74.0)\end{array}$ & $\begin{array}{l}32.1 \pm 10.7 \& \\
(7.6-52.4)\end{array}$ & $\begin{array}{l}59.9 \pm 16.3 \# \& \\
(34.8-90.0)\end{array}$ & $\begin{array}{l}55.6 \pm 19.7 \# \& \\
(11.4-92.1)\end{array}$ & $\begin{array}{l}68.8 \pm 17.9 \& \\
(26.3-99.3)\end{array}$ & $\begin{array}{l}62.7 \pm 21.8 \& \\
(22.2-88.4)\end{array}$ \\
\hline
\end{tabular}

$543 * \mathrm{P}<.05$ (dominant $\neq$ non-dominant).

$544 \# \mathrm{P}<.05$ (U15 $\neq \mathrm{U} 13$ - same limb)

$545 \& \mathrm{P}<.05\left(\mathrm{~T} 30^{\circ} \neq \mathrm{PT} 60^{\circ} / \mathrm{s}\right)$

$546 \mathrm{Mean} \pm \mathrm{SD}(\min -\max )$.

547 SD (standard deviation), min (minimum), max (maximum), PT (peak torque), TW (total work), AVG P (average power), $548 \mathrm{~T} 30^{\circ}$ (torque rated $30^{\circ}$ ) 
558 Table 4. Conventional strength balance ratios (FLEX/EXT) and the angle-specific balance ratio (FLEX $30^{\circ} /$ EXT $30^{\circ}$ ) of age 559 groups U13, U15 and U18.

\begin{tabular}{ccccccc}
\multicolumn{2}{c}{ U13 } & \multicolumn{2}{c}{ U15 } & \multicolumn{2}{c}{ U18 } \\
\hline & Dominant & Non-dominant & Dominant & Non-dominant & Dominant & Non-dominant \\
\hline $\begin{array}{c}\text { FLEX/EXT } \\
\mathbf{6 0} / \mathbf{s}(\%)\end{array}$ & $54.29 \pm 7.68+$ & $53.94 \pm 6.56+$ & $56.38 \pm 5.59+$ & $55.75 \pm 9.48+$ & $56.26 \pm 6.60+$ & $54.67 \pm 5.77+$ \\
& & & & & & \\
& $(36.50-69.56)$ & $(45.17-69.39)$ & $(37.08-66.94)$ & $(44.70-93.13)$ & $(43.81-68.39)$ & $(45.69-65.81)$ \\
$\mathbf{F L E X}$ & $110.80 \pm 73.82$ & $114.67 \pm 55.84$ & $105.03 \pm 38.63$ & $103.36 \pm 36.27$ & $99.88 \pm 22.90$ & $99.16 \pm 36.12$ \\
$\mathbf{3 0} / \mathbf{E X T}$ & & $(37.44-$ & $(54.40-$ & $(24.67-$ & $(59.74-$ & $(42.61-195.02)$ \\
$\mathbf{3 0} \mathbf{6 0} / \mathbf{s}$ & $(37.39-$ & $261.49)$ & $238.23)$ & $193.18)$ & $145.57)$ & \\
$(\mathbf{\%})$ & $341.67)$ & & & & &
\end{tabular}

$560 * \mathrm{P}<.05$ (dominant $\neq$ non-dominant).

$561+\mathrm{P}<.05$ (lower than the reference values $-60 \%$ ).

$562 \mathrm{Mean} \pm \mathrm{SD}(\min -\max )$.

563 SD (standard deviation), min (minimum), max (maximum), FLEX (flexors), EXT (extensors), DM (dominant), NDM (non564 dominant). 